\title{
Research of the College Enrollment Plan Based on Fuzzy Linear Programming Model
}

\author{
Yuhong Sun ${ }^{1, *}$, Guoxing Zhang ${ }^{1}$, Yueyang $\mathrm{Gao}^{1}$ and Mingzhu Chen ${ }^{1}$ \\ ${ }^{1}$ Department of Business Administration, Guangzhou College of Technology and Business, Guangzhou, China
}

\begin{abstract}
This paper aims at the problems of professional structure and hierarchical structure in college admission plans, uses linear programming methods to establish mathematical models, maximizes the use of resources on the basis of completing the national enrollment plan, determines the reasonable enrollment structure and enrollment scale, and makes the enrollment plan more scientific and reasonable. In actual situations, the number of students enrolled in the school, the consumption of students, and the number of teachers are constantly changing. Therefore, the concept of fuzzy linear programming is introduced, and the constraints of the linear programming model are fuzzy optimized to obtain more reasonable results, which inspires some reasonable suggestions for colleges in formulating enrollment plans.
\end{abstract}

\section{Problem description and modeling}

The concept of fuzzy set is first proposed by Zadeh in 1970 [1]. Since then, many scholars have conducted research on it [2-3]. Fuzzy theory has been continuously developed. The basic principle of fuzzy linear programming is to construct a fuzzy target and a set of solutions based on a set of solutions. The fuzzy subset of fuzzy constraints introduces the concept of membership function to represent fuzzy targets and fuzzy constraints, and the method of finding their intersection.

When developing enrollment plan, colleges need to consider how to determine the enrollment scale and enrollment structure in order to realize the rationalization of benefits. However, the enrollment scale will be limited by the school's existing school running conditions, such as classrooms, equipment, dormitory capacity, canteens, and other infrastructure, as well as the faculty and student consumption. The school will also set a certain number of minimum enrollment requirements for sustainable development. The school will also set a certain number of minimum enrollment requirements for sustainable development. Therefore, how to measure the relationship between the school conditions and the enrollment scale is the main problem in formulating enrollment strategy. It can be regarded as a linear programming problem to determine the impact of various factors on the total benefit, and establish a linear programming model [4-6].

\subsection{Select decision variables}

It is necessary to determine the enrollment scale and enrollment structure when formulating the enrollment plan, and set the decision variable $X_{i}(i=1,2, \ldots, n)$ is the enrollment scale of the $i$-th major.

\subsection{Determine the objective function}

The goal of formulating the enrollment plan is to maximize the total benefit, that is, the expression of the relationship between the optimal goal to be achieved and the decision variables, and set the benefit achieved by various professional students is $\mathrm{C}_{i}(i=1,2, \ldots, n)$, then the relationship between them can be expressed as:

$$
\operatorname{Max} Z=C_{1} X_{1}+C_{2} X_{2}+\cdots+C_{n} X_{n}
$$

\subsection{Determine constraints}

Some of the restrictions for the implementation of the enrollment plan are student capacity, faculty strength, student consumption, and the establishment of the minimum enrollment standards. The enrollment size cannot exceed the existing student capacity $V$, which is $\sum_{i=1}^{n} X_{i} \leq V$. The number of classes in the student's course cannot exceed the existing faculty, which is the ratio of the total number of students in the course and the average number of classes in the unit, and is $\frac{\sum_{i=1}^{n} d_{i} X_{i}}{\sum_{i=1}^{n} \sum_{j=1}^{n} B_{i} P_{i j} J}$. The total consumption of students cannot exceed the total investment of students $\sum_{i=1}^{n} D_{i} X_{i} \leq M$; The minimum enrollment standard set by students is $X_{i} \geq R(i=1,2, \ldots$, $n)$; Therefore, the model is:

$$
\operatorname{MaxZ}=C_{1} X_{1}+C_{2} X_{2}+\cdots+C_{n} X_{n}
$$




$$
\left\{\begin{array}{l}
\sum_{i=1}^{n} X_{i} \leq V \\
\frac{\sum_{i=1}^{n} d_{i} X_{i}}{\sum_{i=1}^{n} \sum_{j=1}^{n} B_{i} P_{i j} J} \leq n \cdot N \\
\sum_{i=1}^{n} D_{i} X_{i} \leq M \\
X_{i} \geq R \\
X_{i} \geq 0
\end{array}\right.
$$

Among them, $d_{i}$ is the number of courses studied by the $i$-th major student, $B_{i}$ is the number of classes of the $i$ th major student, $P_{i j}$ is the proportion of the number of students in the combined class of the $i$-th major student $j$, $J$ is the combined class of the class Quantity, $N$ is the school's faculty, $n$ is the number of classes for each teacher, $D$ is the logistics consumption of students, $M$ is the total resource investment amount of the school, and $R$ is the minimum enrollment standard set by the school.

\section{Empirical analysis}

A mixed institution of higher learning recruits full-time undergraduate, junior college and part-time adult education students. The school focuses on undergraduate majors: accounting, business management and financial management; specialty majors: e-commerce and marketing; and adult education majors: English for nursing and business. The number of people in each class is 50 , the undergraduate course is four years, the course to be studied is 64 courses, and the average is 16 courses per year; the college and adult education are three-year courses, and the course for each student is 39 , an average of 13 courses per year; the school's existing faculty has 150 professional teachers and 40 part-time teachers in the enterprise. There are single-class and combined classes for teaching methods. The proportions are also different. Table I shows the detailed data, assuming that a teacher takes 4 classes. The number of students that can be accommodated in the dormitory conditions is 2,500. In addition, students need to consume a certain amount of water, electricity and other resources during school. Due to the different types of student activities, there are certain differences in the logistics consumption costs of students in various majors. At the same time, because the number of student sources and the number of national mission enrollment requirements set a certain number of minimum enrollment, and the school's teacher-student ratio is set at $18: 1$, so in this example, the faculty strength is set to 142 . You can know the annual fees (including tuition and miscellaneous fees) of each major through the professional fee schedule given by the school, as shown in Table II. Under the existing school-running conditions, how to arrange the number and structure of school enrollment to maximize the benefits.
Table 1. Ratio of different students' teaching methods.

\begin{tabular}{|c|c|c|c|}
\hline & Single class & Two classes & Three classes \\
\hline Undergraduate & $70 \%$ & $20 \%$ & $5 \%$ \\
\hline Specialist & $55 \%$ & $30 \%$ & $5 \%$ \\
\hline $\begin{array}{c}\text { Adult } \\
\text { education }\end{array}$ & $40 \%$ & $40 \%$ & $10 \%$ \\
\hline
\end{tabular}

Table 2. School data and fees.

\begin{tabular}{|c|c|c|c|c|}
\hline & Profession & $\begin{array}{c}\text { Cost } \\
\text { (yuan/ } \\
\text { perso } \\
\text { n) }\end{array}$ & $\begin{array}{c}\text { Logistics } \\
\text { consumptio } \\
n \\
\text { (yuan/perso } \\
\text { n) } \\
\end{array}$ & $\begin{array}{c}\text { Minimu } \\
\text { m } \\
\text { enrollme } \\
\text { nt } \\
\text { (person) }\end{array}$ \\
\hline \multirow{3}{*}{$\begin{array}{l}\text { Undergrad } \\
\text { uate }\end{array}$} & Accounting & 8500 & 680 & 500 \\
\hline & $\begin{array}{l}\text { Business } \\
\text { management }\end{array}$ & 8000 & 690 & 90 \\
\hline & $\begin{array}{l}\text { Financial } \\
\text { Management }\end{array}$ & 8300 & 695 & 590 \\
\hline \multirow{2}{*}{ Specialist } & E-commerce & 7500 & 505 & 278 \\
\hline & Marketing & 7000 & 495 & 235 \\
\hline \multirow{2}{*}{$\begin{array}{l}\text { Adult } \\
\text { education }\end{array}$} & Nursing & 4000 & 295 & 70 \\
\hline & \begin{tabular}{|l} 
Business \\
English
\end{tabular} & 5000 & 305 & 340 \\
\hline
\end{tabular}

\subsection{Determine decision variables}

Since the problem to be solved is how to arrange the enrollment of the school to maximize the benefits, the decision variable is the number of students enrolled in the school, and $X_{1}$ is the enrollment of the accounting major; $X_{2}$ is the enrollment of the business administration major; $X_{3}$ is the enrollment number of financial management major; $X_{4}$ is the enrollment number of e-commerce major; $X_{5}$ is the enrollment number of marketing major; $X_{6}$ is the enrollment number of nursing major; $X_{7}$ is the enrollment number of business English major.

\subsection{Determine the objective function}

According to the school fee standard table, assuming that $X_{1}, X_{2}, \ldots, X_{7}$ major students pay $8500,8000, \ldots, 5000$ annually, then the corresponding major incomes are $8500 X_{1}, 8000 X_{2}, \ldots, 5000 X_{7}$. Therefore, the objective function with the largest school income can be expressed as:

$$
\begin{aligned}
Z= & 8500 X_{1}+8000 X_{2}+8300 X_{3}+7500 X_{4} \\
& +7000 X_{5}+4000 X_{6}+5000 X_{7}
\end{aligned}
$$

\subsection{Determine constraints}

1) Limits on student resource consumption: Students need to consume a certain amount of water and electricity resources in the school. Assuming that the total investment of the school is 5000000, and the consumption of various types of students has certain differences, Table II gives the annual consumption of each major student.

2) The number of teachers: Without considering that a teacher takes multiple courses, the number of teachers and the number of classes enrolled by the school consist of a linear relationship between the number of classes composed of course learning, because the students 
have a single class and a combined class Classes, the number of students in each class is 50 , according to the ratio table of various students' class methods, we can know that the ratios of single class, two class and three class of undergraduate students are $70 \%, 20 \%$, and $5 \%$, respectively. The average class size for undergraduate students studying courses is: $50 \times 70 \%+50 \times 2 \times 20 \%+$ $50 \times 3 \times 5 \%$; and because the undergraduate is a four-year program, each course requires 64 courses, and an average of 16 courses are taken each year, so the total number of undergraduate courses is $16\left(X_{1}+X_{2}+X_{3}\right)$. The final determination of the number of classes for undergraduate students can be expressed as: $16\left(X_{1}+X_{2}+X_{3}\right) \div$ $(50 \times 70 \%+50 \times 2 \times 20 \%+50 \times 3 \times 5 \%)$.

In the same way, the number of classes for junior college students can be expressed as: $13\left(X_{4}+X_{5}\right) \div$ $(50 \times 55 \%+50 \times 2 \times 30 \%+50 \times 3 \times 5 \%)$.

The number of classes for adult education students can be expressed as: $13\left(X_{6}+X_{7}\right) \div(50 \times 40 \%+50 \times 2 \times 40 \%$ $+50 \times 3 \times 10 \%$ ).

Further consider that assuming that a teacher takes 4 classes, the constraints on the number of teachers are simplified as $0.256\left(X_{1}+X_{2}+X_{3}\right)+0.2\left(X_{4}+X_{5}\right)+0.173\left(X_{6}+\right.$ $\left.X_{7}\right) \leq 568$.

3) Restrictions on the capacity of the school: Because of the limited area and resources of the school, the classroom, equipment, dormitory capacity and canteen of the school are limited. In this example, the dormitory capacity of the students in the school is 2500 , and all the boarders are undergraduate and junior college students.

4) Enrollment limit: Due to the influence of social development trends, accounting and business English have become popular majors in the school. Considering the existing school running ability and continuous development, it is necessary to limit its enrollment number. Then we build the following model:

$$
\begin{aligned}
Z= & 8500 X_{1}+8000 X_{2}+8300 X_{3}+7500 X_{4} \\
& +7000 X_{5}+4000 X_{6}+5000 X_{7}
\end{aligned}
$$

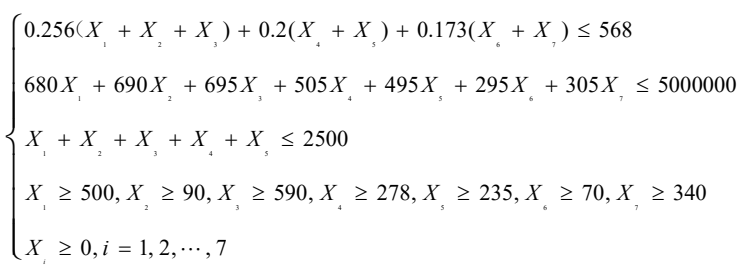

Using MATLAB software programming calculation, the results are as follows:

Optimal solution: $X_{1}=501, X_{2}=170, X_{3}=590, X_{4}=577$, $X_{5}=235, X_{6}=150, X_{7}=340$.

The optimal value: $Z_{0}=18788000$.

The optimal solution obtained above is 501 students for accounting, 170 students for business management, 590 students for financial management, 577 students for e-commerce, 235 students for marketing, 150 for nursing Students, 340 students are enrolled in Business English, and a total of 2563 students are enrolled, and the maximum total income achieved is 18788000 yuan.

\section{Model optimization}

In the above example, the linear programming method is used to establish a mathematical model. Under the existing school running conditions, the enrollment scale and enrollment structure that maximized the benefits are obtained, which is used as the basis for decision-making in the college enrollment plan. However, in actual situations, because the number of students enrolled cannot be accurately controlled, the consumption of students is ambiguous, and the number of teachers is also constantly changing. Therefore, in the actual situation, the above linear programming model has objective functions and constraints. Some degree of ambiguity. Define the scaling index according to the constraints in the above formula: $d_{1}=40, d_{2}=200000, d_{3}=300, d_{4}=20, d_{5}=30, d_{6}=40, d_{7}=30$, $d_{8}=30, d_{9}=30, d_{10}=20$, establish a linear programming model:

$$
\begin{aligned}
Z= & 8500 X_{1}+8000 X_{2}+8300 X_{3}+7500 X_{4} \\
& +7000 X_{5}+4000 X_{6}+5000 X_{7}
\end{aligned}
$$

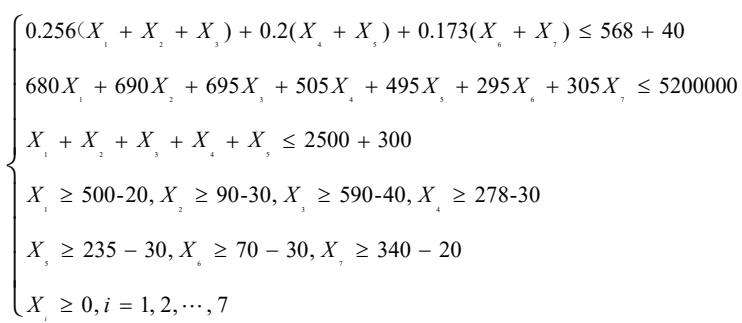

Using MATLAB software programming calculation, the results are as follows:

Optimal solution: $X_{1}=480, X_{2}=140, X_{3}=550, X_{4}=965$, $X_{5}=205, X_{6}=120, X_{7}=322$.

The optimal value: $Z_{1}=20527000, \quad d_{0}=Z_{1}$ $Z_{0}=20527000-18788000=1739000$.

Therefore, the linear programming problem under fuzzy optimization is transformed into a parametric programming model for solution:

$$
\operatorname{Max} S=\lambda
$$

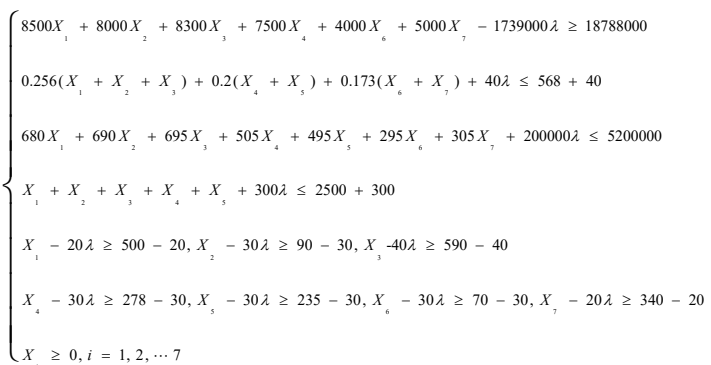

Using MATLAB software programming calculation, the results are as follows:

Solutions have to: $\lambda=0.5, X_{1} *=492, X_{2}^{*}=155, X_{3}^{*}=570$, $X_{4} *=769, X_{5}^{*}=221, X_{6}^{*}=135, X_{7}^{*}=330$.

$Z=492 \times 8500+155 \times 8000+570 \times 8300+769 \times 7500+221$ $\times 7000+135 \times 4000+330 \times 5000=19657500$.

$Z-Z_{0}=19657500-18788000=1687900$.

A common understanding of the ambiguity is that 492 students in accounting, 155 students in business management, 570 students in financial management, 769 
students in e-commerce, 221 students in marketing, and nursing Professional enrollment of 135 students, business English enrollment of 330 students (as shown in Table III), the ultimate total income achieved is 19657500 yuan.

Table 3. College admissions schedule.

\begin{tabular}{|l|l|c|}
\hline & profession & Planned enrollment \\
\hline \multirow{3}{*}{ Undergraduate } & Accounting & 492 \\
\cline { 2 - 3 } & Business management & 155 \\
\cline { 2 - 3 } & Financial Management & 570 \\
\hline \multirow{2}{*}{ Specialist } & E-commerce & 769 \\
\cline { 2 - 3 } & Marketing & 221 \\
\hline $\begin{array}{l}\text { Adult } \\
\text { education }\end{array}$ & Nursing & 135 \\
\cline { 2 - 3 } & Business English & 330 \\
\hline
\end{tabular}

Therefore, when the enrollment plan is formulated according to the school's operating conditions, when the number of students enrolled, the number of teachers, and the consumption of students are all vague and flexible, the school's investment can be appropriately increased, and the enrollment scale of students can be increased to achieve greater Benefits. Therefore, the final enrollment plan can be determined, as shown in Table III.

\section{Conclusions}

This article focuses on how to formulate a reasonable enrollment structure and enrollment scale under the existing resources and constraints, and builds a mathematical model using the MATLAB software to solve the problem. The enrollment structures and enrollment scale under the general linear model are obtained. In order to further to consider the actual situation Under the circumstances, the search plan is formulated, the model is optimized on the basis of the existing mathematical model, the fuzzy theory is introduced, and the boundary of the constraint is blurred, so that the decision-making of the college when making the enrollment plan is more reasonable, and the final college is obtained. The enrollment plan is: 492 students in accounting, 155 students in business management, 570 students in financial management, 769 students in ecommerce, 221 students in marketing, 135 students in nursing, and business English enrolls 330 students. It further improves the application of the model in the actual situation, and combines the scientific methods of linear programming with the college admissions plan, which is of great significance to increase the scientific rationality of decision-making.

The establishment of the current model mainly considers the capacity of the student dormitory in the school, the level of school investment, the number of national task enrollment, the faculty and the number of courses learned. The factors considered are still lacking, and the assumptions are still too idealistic. The analysis method makes the plan made inflexible to a certain extent, and can only be used as a limited reference. The control and adjustment flexibility of the college admission plan model is still to be discussed by scholars.

\section{Acknowledgment}

All simulations were carried out using the equipment provided by Gansu Provincial Computing Center.

\section{References}

1. R. E. Bellman, L. A. Zadeh. Management Sci., 17, (1970)

2. B. Werners. Fuzzy Sets \& Systems, 23, (1987)

3. A. M. A. Bertone, R. S. D. M. Jafelice. Tema, 18 (2017)

4. S. K. Das, S. A. Edalatpanah, T. Mandal, Journal of computational ence, 25, (2018)

5. Z. T. Gao, T. G. Wang. IOP Conference Series: Earth and Environmental Science, 463, (2020)

6. K. Sandeep, International Journal of Systems Science: Operations \& Logistics, 7, (2020) 